\title{
Some Thoughts on the "Ex-offender reentry" Protection Social Organization in Taiwan, China
}

\author{
—_A Case Study of "Ex-offender reentry" M of the Social Organization G \\ in Taipei \\ Liyao $\mathrm{Xiao}^{1, \mathrm{a}}$ \\ ${ }^{1}$ Binshui Road No. 391,XiQing District,Tianjin City,China \\ azzxiaoliyao@163.com
}

Keywords: Ex-offender reentry; Social organization; Social identity

\begin{abstract}
Ex-offender reentry" is a individual-based appellation, while the other meaning of the released prisoners is still stressed on his past, which is a social-based appellation. "Ex-offender reentry" Protection Social Organization entitles the "ex-offender reentry" new identity and positive social identity, which embodies a more positive group characteristics. In fact, this is an export of contradictory identity of released prisoners in the community. Based on the two-dimensional model of social identity (evaluation-relationship), this paper puts forward the macroscopic social background to be focused on by a case study of ex-offender reentry" $M$ who succeeded in adapting society from social organization G. Finally, this paper puts forward some thoughts on the "ex-offender reentry" protection social organization in Taiwan, China.
\end{abstract}

\section{Introduction}

"Ex-offender reentry" refers to those who are released from prison after serving sentences because of their crimes. They are called "ex-offender reentry" in Taiwan, while they are called "people who are released from prison" on mainland. The call of "Ex-offender reentry" in Taiwan is an negative label expression. Just as its name implies, it hopes that after being released from prison, this group can uphold the attitude of self-reliance to face society and life. China's Taiwan social organizations have participated in protecting ex-offender reentry for many years, so it is more mature. In April, 1976 Taiwan has promulgated the In April 1976, Taiwan promulgated the Law on the Protection of Rehabilitation, the Rules for the Implementation of the Law on the Protection of Rehabilitation, the Constitution of the Taiwan Living Protection Council. Thus, there is law to follow when protecting prisoners released. In addition, the Taiwan authorities gave the social organizations a lot of support. It has developed lots of models, such as "social workers involved" "family rehabilitation" "public placement for the ex-offender reentry" and other models. Except for the semi-official social organizations that are authorized by the government to be responsible for the protection of the survivor, there are 531 social organizations directly involved in protecting ex-offender reentry to live alone in Taipei, which accounts for $13 \%$ of the total number of social organizations[1]. These all made a real difference to the socialization of protecting ex-offender reentry.

It is an aim for G organization to accept, accompany, counsel "ex-offender reentry" to return to the family, the workplace, and train them into the social welfare cause. "Ex-offender reentry" Protection Social Organization was established in 2003, whose founder is a couple of Christians Liu Hao, Lin Yunmin. The association has accepted more than 400 "ex-offender reentry" since they began to accept the first batch of "ex-offender reentry" to the end of 2015, for more than 10 years. 
At present, in addition to the chairman and CEO, G organization has 15 association directors, 5 supervisors, and 7 other administrative staff, 10 drug counseling and anti-drug propaganda workers. G organization protects "Ex-offender reentry" from many aspects,including addiction counseling, anti-drug propaganda, common life, education and training, and it now opens a coffee shop, garden landscape restaurant, handicraft workshop and other enterprises. At present, the $G$ organization has become the leader of Taiwan's "Ex-offender reentry" Protection Social Organization.

\section{Research Approach}

\subsection{Research Design}

This study uses semi-structured interviews to conduct in-depth interviews with the case by skimming verbatim, coding, giving meaning and content analysis. Although this paper is a case study approach, it still strives to focus on from the individual to the members of the group. Connected with the social experience of the case, this study analyzed the transformation of the unit from the theory to the experience.

\subsection{Analysis Framework}

Social identity theory was first proposed by Tajfel. Social identity is defined as: "Individuals know that he or she belongs to a particular social group and that the group membership he or she obtains gives it some emotional and value meaning" (Tajfel, 1972a: 31 )[3]. Social identity theory holds that each person's self-identity is largely composed of the constant description of itself, and the constant description of itself is largely influenced by the characteristics of the group to which it belongs. "belongingness" is psychologically, not just about the characteristics of a particular group[2] . To identify a group is a psychological state that is completely different from that of being assigned to this or that social category.

\subsection{Case Description}

$\mathrm{M}$ is a 46-year-old man who successfully completed the social adaptation to engage in anti-drug work after being released from prison for 10 years. His educational level was high school. He is a Taiwan Keelung man. From the 16 to 36 years old, the last time released from prison, he had been repeatedly imprisoned for 16 times because of drug trafficking in the last 20 years. The longest imprisonment lasted for three years and seven months. And after being released from the $G$ organization, he is now engaged in rehabilitation counseling Staff work. He leads the "ex-offender reentry" students to participate in corporate labor and physical and psychological detoxification courses. "Ex-offender reentry" avoid the short term to accept all multiple pressures from drug addiction, social exclusion, and stigma. He has won the Taiwan region "anti-drug active person" title. His family member includes his mother and two children. The two children have been working.

\section{The Shape of "Ex-offender reentry" Group Identity}

The inner two-dimensional path of social identity holds that only when the group agree and think that self belongs to a group at the same time, can the group have a positive state of integration. In the prison, $\mathrm{M}$ tried to adapt o accept the reality, and he has completed the integration of the prisoners. M said, " people in prison are called the prison, and most of us are these people," he thinks he belongs to this group. The highly closed prison is different from the normal open society, so that criminals in the process of integration into the prison forget how to return to society in the future. 
After being released from prison, $M$ was introduced into the $G$ organization. $M$ has always stressed that being into social organization is a turning point in his life, and found the power of life through getting along with other "ex-offender reentry". The "ex-offender reentry" identity is an approach that $\mathrm{M}$ change his own contradictions and identity. The statements such as "satisfy" "happy", "pleased" have shown that "ex-offender reentry" have positive identity of their own identity. On the one hand, after the release of $\mathrm{M}$, the main trajectory of life is to learn, live and work with other "ex-offender reentry" in the organization. He thinks he is very similar to "brother" and has "crime Imprisonment memory ", but are positive, eager to self-reliance. At the same time, M's values have been rebuilt in the organization. "After coming to this institution, you will feel that you are loved, and when you are loved, you will need to grow, so that you can restore your past vitality." When you grow to a stage after you have to play (their own ability), so (for the community) you should be responsible to care for others and help others. In the words he said, we can see that "helping others", " responsibility" is the most basic element of this group's evaluation for M. And it is felt that joining the organization and living with others is completely different from that of the group. The organization creates the core culture of the "ex-offender reentry" group. Where M even think that "crime imprisonment" is "accidental gift", for he will have transformed negative experience as now work "pre-job training". "Now we have a lot of brothers. When one becomes better, he will help others. $\mathrm{M}$ gives highly comment to "ex-offender reentry". In their social comparisons, and they have gradually developed in the life of the organization. During their life in the organization, $M$ 's "ex-offender reentry" identity of two latitudes of" living in new life " developed and constructed together, $\mathrm{M}$ performed positively to integrate into the organization.

Self-categorization accomplishes two things at the same time. First, M puts himself in the field of "ex-offender reentry" group, or puts this group consciousness into his mind. Second, the process of self-categorization makes M's behaviors match the group's consciousness. $M$ said in the organization "to carry out self-social responsibility", and these social responsibility is engaged in public welfare cause, which is "ex-offender reentry" group of self-demands. It can be said that the organization of $\mathrm{M}$ is to help them get a positive "ex-offender reentry" identity base. This may be the reason why $\mathrm{M}$ decided to stay in the organization after succeeded in drug rehabilitation.

\section{Eager to Get Positive Recognition in More Social Areas}

In order to meet the needs of self-esteem, individuals will highlight some of the expertise. Therefore, the individual self-motivation in the group will make the individual perform better than other members do in the relevant dimensions of groups comparison. $\mathrm{M}$ take the initiative to me that he won "anti-drug active person". "Now their identity has been raised to a stage", for they got individual recognition from the community and the official. M thinks that their "identity "has also been improved. $\mathrm{M}$ is a counselor of ex-offender reentry, and he is also a "ex-offender reentry". It can be explained as the follows, by actively distinguishing yourself between those ex-offender reentry who are "still hesitating in blind spots". M advocates anti-drug, and strives to create performance, so he become the leader among "ex-offender reentry ", which makes $\mathrm{M}$ now have "identity". This process is also the source of his life value.

After M succeeded in integrating into the "ex-offender reentry" group, he hoped to get positive recognition in other social roles. "I am an irresponsible father". M refers here to the "father" in the broad sense. He refers to his family, including the social role that "husband" should play. The breadwinner is a label in the category of social society. And social identity recognizes $\mathrm{M}$ as a 
member of "irresponsible" in the process of self-categorization. Because he considers that he does not conform to the behavioral pattern of the society. "I'm going to make up my previous qualifications." "Now I just want to finish what I did not finish." Self categorization plays a key role here. And the social population is similar, while $\mathrm{M}$ is characterized by a pattern of behavior that tends to be close to this group, and social values are the criteria for judging how a society behaves. At this point, we can see that $\mathrm{M}$ is more agreeable to the society itself, but his relationship with the society should be improved.

By analyzing the above, we can see that M's positive social identity is not satisfied with the acquisition of a single role, but attempts to co-construct from multiple fields. $\mathrm{M}$ choose to spend a lot of energy to make up for family relationships, and choose to continue to finish high school to get high school diploma. The behind connotation can be analyzed as this: good family relationship and high school diploma are symbols of the society. The incentive due to which M tries to "make up" comes from the sense of isolation brought by the before comparison between the prisoners identity and the social people. Under the influence of the mainstream social groups, $\mathrm{M}$ tries to be close to the social groups. Contradictory social identity and criminal identity will not be long lasted. M actively integrated into the "ex-offender reentry" group through the organization, and then improved the construction of the "social people" role through a number of areas. And ultimately, a relatively steady and positive recognition result was showed .

\section{Discussion}

\section{1 "Ex-offender reentry" Protection Social Organization Reshapes the Identity of "Released Prisoners"}

"The released prisoners" the title itself create a "lingering relationship" between the "released prisoners" and "social people", that is, because of this label, " released prisoners" are difficult to get rid of the prisoners' past memories, so that in the process of "re-socialization",there is always stumbling. The identity of the released prisoners; role is always swinging between the "released prisoners" and "social people". Because the work of education that our country sets for the released prisoners is mainly operated from the perspective of social management. Therefore, there are many circumstances that the "released prisoners" will slip to the "prisoners" identity. The study found that "Ex-offender reentry" Protection Social Organization actually creates a transitional "ex-offender reentry" role in the two roles identity. The life in the organization and social propaganda reinforce its positive cultural foundation, which is more conducive to the released prisoners into this group. "Ex-offender reentry" is a individual-based appellation. While the meaning of the "released prisoners" is still stressed that his past, this is a social-based appellation. Social organizations have given the "ex-offender reentry" new identity and positive social identity. It is more positive than the criminals. However, from the nature of the group, we can see in the face of the mainstream values of society, "ex-offender reentry" is a subsidiary group from the social resources, and the relationship between the status of power. In the study, $\mathrm{M}$ had a contradictory self-description on the "responsible". On the one hand, $\mathrm{M}$ thinks that as a "ex-offender reentry, he is responsible. And as a "social person", (such as as a "breadwinner") he is not responsible enough, for he has missed most of the time getting along with the children, not to carry out social responsibility. Therefore, due to the reality, the released prisoners are difficult to fully have a positive "social" identity. The positive integration of the " released prisoners " to the "ex-offender reentry" groups has circumvented the wandering state between the "prisoners" and "social people". The relative 
sense of deprivation (compared with the social people) is the main reason for the crime. The "Ex-offender reentry" Social Organization provides a gentle way of transferring contradictory in the case of the relative deprivation of objectivity in the society, In fact this is an approach that the released prisoners in society get the contradiction identity. Meanwhile, there is condition for choosing identity freely, which is determined by the social environment. If there is no "Ex-offender reentry" Social Organization, the individual will also be very difficult to choose "ex-offender reentry" identity.

\subsection{To Broaden the Channels of Positive Identity}

The study found that in order to balance the reality and expectations of the status of identity, $\mathrm{M}$ will continue to look for the categorical properties that have the advantage over him. M thinks that the acquisition of "anti-drug active man" improved his "identity". When the released prisoners can not get rid of the negative low status of the group identity, the individual will adopt some strategies to enhance his positive identity within the group, including social creation and social competition. So the diversified positive identity of access channels are particularly important. The path of the detainees to obtain positive identity is diversified. Therefore, it is necessary to broaden the channels of access for prisoners to get positive identity in society. First of all, we should help the prisoners get the right to speak, so that they have a certain voice channels to express themselves. Secondly, we can imitate the work of social organizations in Taiwan to guide some of the excellent released prisoners to create associations, and encourage participation in social welfare and other social activities.

\section{References:}

[1] Taiwan Social Organizations Development Study Report. CPC Zhejiang Provincial Committee "Two New" Work Committee, Zhejiang Province Social Organization Promotion Meeting to Taiwan Inspection Group

[2] Guo Xinghua, Xing Zhaoguo. Intrinsic Two-dimensional Schema of Social Identity - Taking the Social Identity of Peasant Workers in Beijing as an Example [J]. Jiangsu Social Sciences, 2009

[3] The Process of Social Identity. Michael.A.Haug writes, Gao Minghua translates. China Renmin University Press, 2011 